\title{
High-rate low-temperature growth of vertically aligned carbon nanotubes
}

Shang, NG., Tan, YY., Stolojan, V., Papakonstantinou, P., \& Silva, SRP. (2010). High-rate low-temperature growth of vertically aligned carbon nanotubes. Nanotechnology, 21, 505604. https://doi.org/10.1088/0957$4484 / 21 / 50 / 505604$

Link to publication record in Ulster University Research Portal

\section{Published in:}

Nanotechnology

Publication Status:

Published (in print/issue): 23/11/2010

DOI:

10.1088/0957-4484/21/50/505604

\section{Document Version}

Publisher's PDF, also known as Version of record

\section{General rights}

Copyright for the publications made accessible via Ulster University's Research Portal is retained by the author(s) and / or other copyright owners and it is a condition of accessing these publications that users recognise and abide by the legal requirements associated with these rights.

\section{Take down policy}

The Research Portal is Ulster University's institutional repository that provides access to Ulster's research outputs. Every effort has been made to ensure that content in the Research Portal does not infringe any person's rights, or applicable UK laws. If you discover content in the Research Portal that you believe breaches copyright or violates any law, please contact pure-support@ulster.ac.uk. 
High-rate low-temperature growth of vertically aligned carbon nanotubes

This article has been downloaded from IOPscience. Please scroll down to see the full text article.

2010 Nanotechnology 21505604

(http://iopscience.iop.org/0957-4484/21/50/505604)

View the table of contents for this issue, or go to the journal homepage for more

Download details:

IP Address: 193.61.144.19

The article was downloaded on 24/11/2010 at 09:19

Please note that terms and conditions apply. 


\title{
High-rate low-temperature growth of vertically aligned carbon nanotubes
}

\author{
N G Shang ${ }^{1,3}$, Y Y Tan ${ }^{1}$, V Stolojan ${ }^{1}$, P Papakonstantinou ${ }^{2}$ and \\ S R P Silva ${ }^{1,3}$ \\ ${ }^{1}$ Nano-Electronics Centre, Advanced Technology Institute, University of Surrey, Guildford, \\ Surrey GU2 7XH, UK \\ ${ }^{2}$ Nanotechnology and Integrated Bio-Engineering Centre, University of Ulster, Shore Road, \\ Newtownabbey BT37 0QB, UK \\ E-mail: n.shang@hotmail.com and s.silva@ surrey.ac.uk
}

Received 8 August 2010, in final form 6 October 2010

Published 23 November 2010

Online at stacks.iop.org/Nano/21/505604

\begin{abstract}
We report the low-temperature growth of vertically aligned carbon nanotubes (CNTs) at high growth rates by a photo-thermal chemical vapour deposition (PTCVD) technique using a Ti/Fe bilayer film as the catalyst. The bulk growth temperature of the substrate is as low as $370{ }^{\circ} \mathrm{C}$ and the growth rate is up to $1.3 \mu \mathrm{m} \mathrm{min}^{-1}$, at least eight times faster than the values reported by traditional thermal CVD methods. Transmission electron microscopy observations reveal that as-grown CNTs are uniformly made of highly crystalline 5-6 graphene shells with an approximately $10 \mathrm{~nm}$ outer diameter and a 5-6 nm inner diameter. The low-temperature rapid growth of CNTs is strongly related to the unique top-down heating mode of PTCVD and the use of a Ti/Fe bimetallic solid solution catalyst. The present study will advance the development of CNTs as interconnects in nanoelectronics, through a CMOS-compatible low-temperature deposition method suitable for back-end-of-line processes.
\end{abstract}

(Some figures in this article are in colour only in the electronic version)

\section{Introduction}

Carbon nanotubes (CNTs) have exhibited unique electrical, thermal and mechanical properties such as high current density and ballistic transport, and thus are potential candidates for replacing $\mathrm{Cu}$ interconnects in nanoelectronics, where $\mathrm{Cu}$ nanoscale wirings fail to meet the predicted current density demands imposed in large scale integration circuits of the future $[1,2]$. However, present CMOS devices are fabricated with back-end-of-line processes at temperatures below $400{ }^{\circ} \mathrm{C}$, which is a challenge for growing high-quality CNTs by chemical vapour deposition (CVD), even though CVD has been proved to be a location-selective and orientationcontrollable growth method at bulk scale. The main reason is that catalysts cannot be restructured and activated, and reactive species cannot be dissociated and reacted with catalysts at such low substrate temperatures based on a traditional bottom-up heating approach. To date, three routes have been attempted to lower the CNT growth temperature: (1) using various

3 Authors to whom any correspondence should be addressed. carbon feedstocks with lower dissociation temperature and high reaction activity with catalysts [3], (2) exploring a wide range of catalysts, such as bimetallic nanoparticles and oxides with low melting points $[1,4,5]$ and (3) introducing a plasma during deposition with the scope of increasing the dissociation and ionization of feed gases and concomitantly decreasing the activation energy of the CNT growth $[6,7]$. However, plasma-based methods inevitably introduce structural defects into CNTs due to ion bombardment, leading to the formation of lower-quality carbon nanofibres $[8,9]$. Meanwhile, due to plasma poisoning of catalysts and etching of CNTs, plasma methods do not favour the growth of both high-quality singlewall CNTs and ultralong multi-wall CNTs [10]. Traditional thermal CVD methods are still good candidates for lowtemperature growth of CNTs by using gas preheating, catalyst pretreatment, etc $[11,12]$. However, the present growth rate of CNTs by thermal CVD is quite low and insufficient for practical applications of CNTs. Therefore, it is necessary to develop highly efficient methods to grow high-quality CNTs at low temperature for the integration of CNTs into CMOS devices. Here, we demonstrate the low-temperature rapid 
growth of vertically aligned CNTs by a novel photo-thermal CVD (PTCVD) method using a highly active Ti/Fe alloy catalyst. The structure of as-grown CNTs is studied by using scanning electron microscopy (SEM), transmission electron microscopy (TEM) and Raman scattering. The rapid growth mechanism of CNTs is discussed briefly. The field emission properties of CNTs are investigated at room temperature.

\section{Experimental details}

Figure 1 shows a schematic diagram of the photo-thermal CVD system (Surrey NanoSystems) [13, 14]. The new photo-thermal growth process consists of a halogen lamp array situated approx. $10 \mathrm{~cm}$ above the water cooled lowtemperature sample stage which is CMOS back-end-of-line process-compatible. The lamp array is separated from the chamber and cooled by flowing $\mathrm{H}_{2} / \mathrm{He} / \mathrm{N}_{2}$ gas. The maximum power of each lamp is one kilowatt and is computer-controlled to set up the lamp and substrate temperature as required by the process. The energy balance between the heat energy delivered by the lamp array and the heat removed by the water-cooled electrode is finely controlled by the thermal barrier layer above the substrate [14]. The whole system consists of many program modules such as the lamp temperature, substrate temperature, pressure, gas flow, cooling water, etc, which are feedbackcontrolled. Unlike traditional thermal CVD, photo-thermal CVD is a top-down method allowing energy delivery directly to the catalyst and hence substrate temperature-controlled at an appropriately low level. It enables a high rate of heating for structuring the finest catalysts, leading to highly efficient growth of CNTs. A tri-layer film of $50 \mathrm{~nm} \mathrm{SiO} 2,1 \mathrm{~nm} \mathrm{Fe}$ and $0.5 \mathrm{~nm}$ Ti was sequentially deposited on $\mathrm{Si}$ by magnetron sputtering. The sample was loaded into the growth chamber in air. After pumping down to its base pressure, a mixture gas of $100 \mathrm{sccm} \mathrm{H}_{2}$ and $6 \mathrm{sccm} \mathrm{C}_{2} \mathrm{H}_{2}$ was introduced into the chamber at a working pressure of 2 Torr. Then the top lamp array was switched on to immediately start the CNT growth for $15 \mathrm{~min}$. The substrate temperature was continuously monitored by an optical pyrometer embedded in the sample holder, which was pre-calibrated by a thermocouple located on the surface of the Si substrates. After deposition, the lamp array was switched off and the sample was cooled in the ambient of $\mathrm{H}_{2}$.

\section{Results and discussion}

Figures 2(a) and (b) show a top-view and cross-sectional SEM images of the CNT sample grown at a substrate temperature of about $370^{\circ} \mathrm{C}$. The surface is uneven with the appearance of some cross-protruding lines, which are not horizontal CNT bundles but the tips of vertically aligned CNTs due to different CNT heights confirmed by high-magnification SEM inspection (figure 2(d)). They follow the scratches on the catalyst-coated substrate prior to the CNT deposition, confirmed by atomic force microscopy (AFM) observations (figure 5(a)). These findings point to the fact that the CNT growth follows a tip growth model [15] and the growth temperature is relatively low as no surface-melting-induced flattening of the metal catalysts appears to occur on the substrate. The length of CNTs is

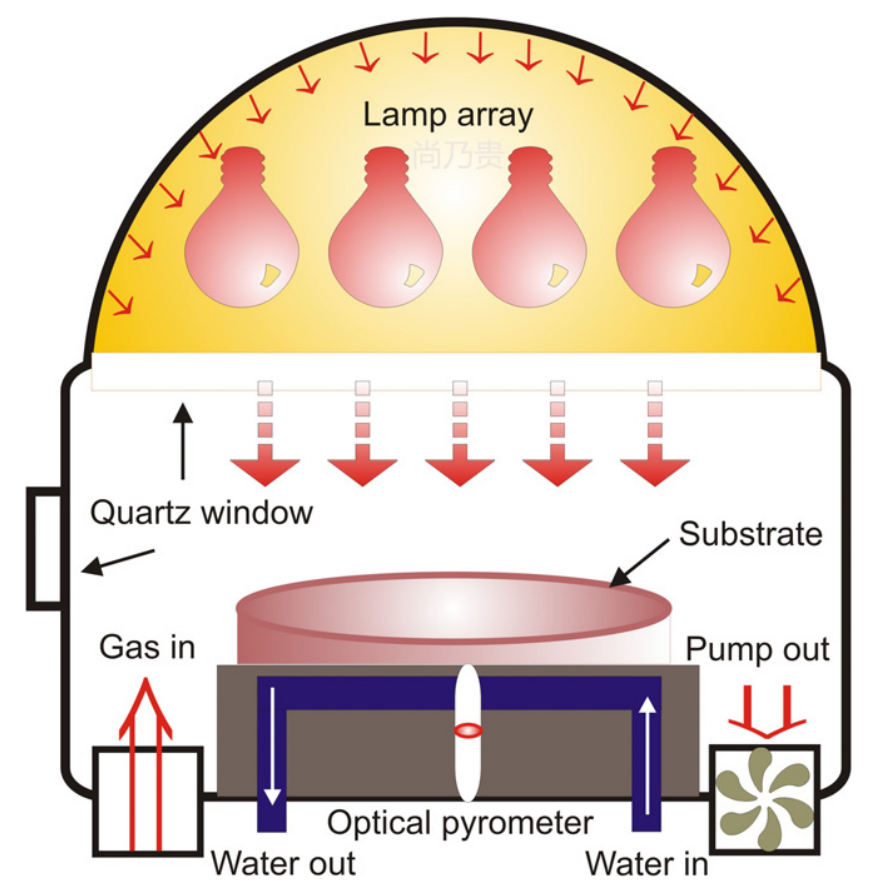

Figure 1. Schematic diagram of the PTCVD system.

about $20 \mu \mathrm{m}$ and the growth rate is calculated as approx. $1.3 \mu \mathrm{m} \mathrm{min}^{-1}$. This value is about $8-25$ times larger than that of traditional thermal CVD $\left(0.05-0.16 \mu \mathrm{m} \mathrm{min}^{-1}\right)$ in the substrate temperature range of $350-475^{\circ} \mathrm{C}[11,12]$. The asgrown CNTs via PTCVD are in the form of a forest with vertically aligned bundles with respect to the $\mathrm{Si}$ substrate. They are clean, with no carbon particles and residual catalysts found among the CNT forest as shown in figure 2(e). This was further confirmed by the scanning back-scattering electron imaging technique, which is more sensitive to heavy metal catalysts than to the lighter element carbon [16]. Figures 2(c) and (f) show scanning secondary and back-scattering electron images, respectively, taken from the same top cross-sectional area of the sample, where energy dispersive x-ray analysis shows the presence of $\mathrm{Fe}$ and $\mathrm{Ti}$ metal catalysts (not shown here). However, a few bright spots related to the metal catalysts are found in the back-scattered electron image on both the tip and side areas of CNTs. This reveals the catalysts are tiny and uniform. Due to their small size, we believe they always retain a high activity for catalytically growing CNTs.

Figure 3(a) shows a low-magnification TEM image of the sample, which is prepared by ultrasonicating in methanol and then filtering through a holey carbon grid. The sample is very clean and contains few contaminant particles. It only consists of tangled long CNTs with uniform diameters. The electron diffraction pattern in the inset is matched well with that of polycrystalline hexagonal graphite, revealing that the as-grown CNTs are highly graphitized. Figure 3(b) is a typical highresolution TEM image of an as-deposited CNT. The CNT has a 5-6 nm hollow interior and about $10 \mathrm{~nm}$ outside diameter. It is clearly made of 5-6 graphene shells, which have a typical graphite (0002) spacing of $0.347 \mathrm{~nm}$. The constituent graphene layer is essentially crystalline but contains various structural defects, which are similar to those found in CNTs grown by 

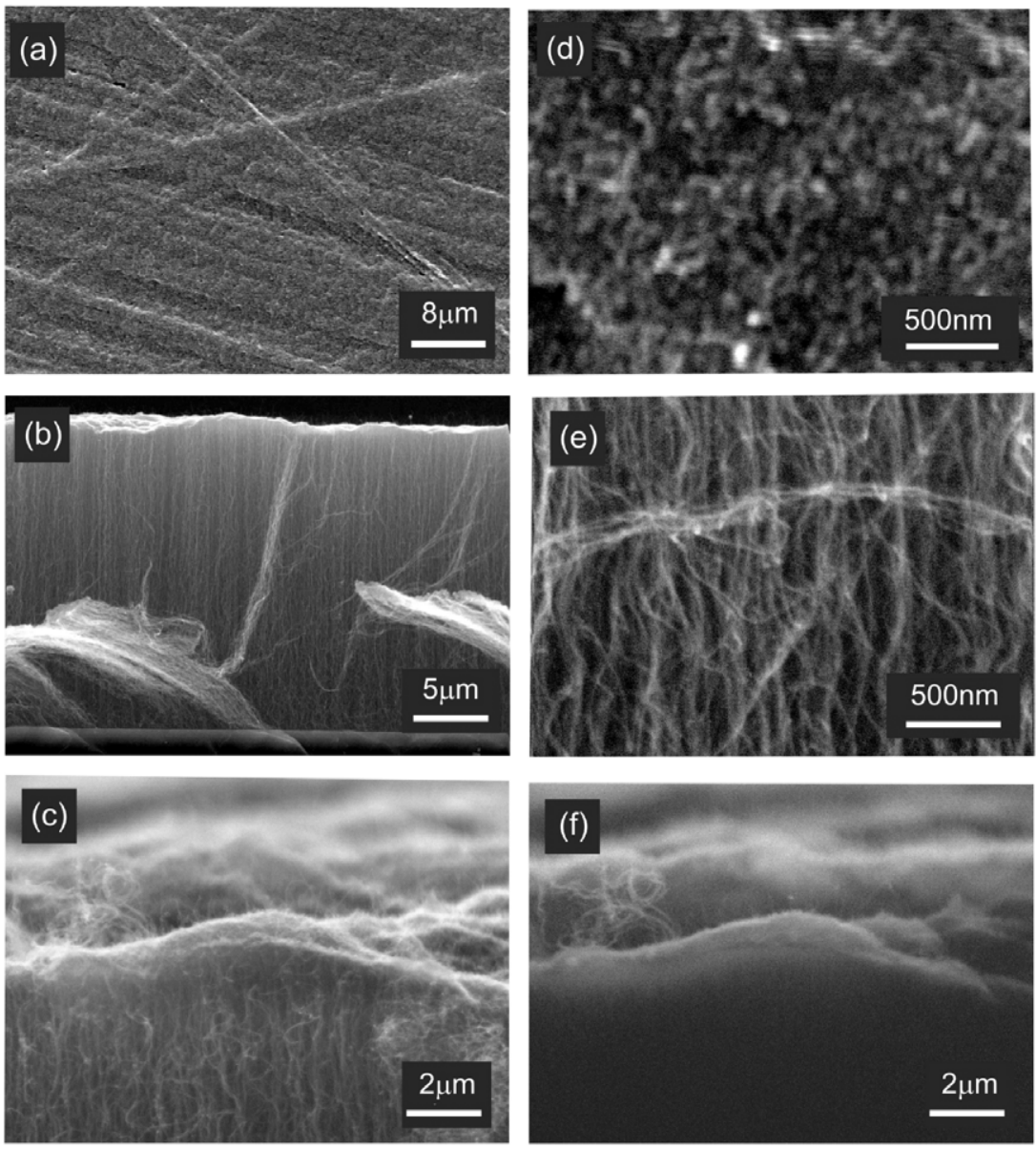

Figure 2. Top-view (a) and cross-sectional (b) SEM images of vertically aligned CNTs; (d) and (e) are the enlarged images of (a) and (b), respectively; (c) and (f) are scanning secondary and back-scattering electron images, respectively.

other methods at low temperatures $[1,12]$. For example, there are some broken graphene layers, forming some steps and kinks along both the inner and outer walls of CNTs (pointed out by a double-line arrow). There are also some rippled graphene layers formed on the inner side of CNT walls (identified by an arrow) because the stress in the wall cannot be released at low temperatures. Meanwhile, some carbon onions or fullerenes are found on the outer wall of CNTs. These structural defects destroy the periodicity of graphene shells and make both the inner and outer walls defective and rougher compared to high-temperature grown or annealed CNTs, whose walls are commonly made of clean, straight, ordered and highly crystalline graphene layers.

Figure 4(a) shows the Raman spectra at room temperature excited by multiple-wavelength lasers of 2.81 (442 nm), 2.41 $(514 \mathrm{~nm}), 1.96(633 \mathrm{~nm})$ and $1.58 \mathrm{eV}(782 \mathrm{~nm})$ in the range of $500-3000 \mathrm{~cm}^{-1}$. Their profiles are very similar to those of CNTs grown by both thermal and plasma-enhanced CVD at substrate temperatures of $400-550{ }^{\circ} \mathrm{C}[17,18]$. The spectra mainly consist of three bands: a $\mathrm{D}$ band at $1307.5-1358.0 \mathrm{~cm}^{-1}$, a $\mathrm{G}$ band at $1571.1-1594.2 \mathrm{~cm}^{-1}$ and a $\mathrm{G}^{\prime}$ band at $2597.2-2717.0 \mathrm{~cm}^{-1}$, possibly including a $\mathrm{D}^{\prime}$ shoulder at $1600-1620 \mathrm{~cm}^{-1}$. The intensity of the D band is increased with the excitation wavelength, while the intensity of the $G^{\prime}$ band is decreased. Due to the double resonance effect [19], the frequencies of both $D$ and $G^{\prime}$ bands are upshifted with the excitation energy shown in figure 4(b). They have an energy dispersive coefficient of 40.7 and $98.2 \mathrm{~cm}^{-1} \mathrm{eV}^{-1}$, respectively, both smaller than the majority of reported values on graphite and single-wall CNTs. In terms of the nature of the $\mathrm{D}$ band from the structural defects in graphene-based materials, the ratio $\left(I_{\mathrm{D}} / I_{\mathrm{G}}\right)$ of integrated intensities of the $\mathrm{D}$ to $\mathrm{G}$ bands usually has been considered as a fingerprint for the evaluation of the crystal quality of graphenebased materials. The $I_{\mathrm{D}} / I_{\mathrm{G}}$ ratios of $\mathrm{D}$ to $\mathrm{G}$ bands for four kinds of laser excitations of 442, 514, 633 and $782 \mathrm{~nm}$ are $0.8,1.3,2.0$ and $3.0-6.5$, respectively. The ratio is increased with the excitation wavelength, as observed in other graphitic materials [20]. The ratio with the $782 \mathrm{~nm}$ laser excitation is not well defined, because the $\mathrm{D}^{\prime}$ and $\mathrm{G}$ bands cannot be distinguished well due to the resonant excitation. Meanwhile, a broad peak related to amorphous carbon at about $1500 \mathrm{~cm}^{-1}$ is also activated by the $782 \mathrm{~nm}$ laser and thus significantly influences the intensity of the $\mathrm{G}$ band. Thus, to accurately evaluate graphene-based materials, the comparison of both the $\mathrm{D}$ band intensity and the $\mathrm{D}$ to $\mathrm{G}$ band ratio for different samples should be based on identical laser excitation. Here, the ratio $\left(I_{\mathrm{D}} / I_{\mathrm{G}}=1.3\right)$ for the $514 \mathrm{~nm}$ excitation from our samples is less than that $\left(I_{\mathrm{D}} / I_{\mathrm{G}}=3.4\right)$ of CNTs deposited by radio-frequency plasma CVD at a substrate temperature 

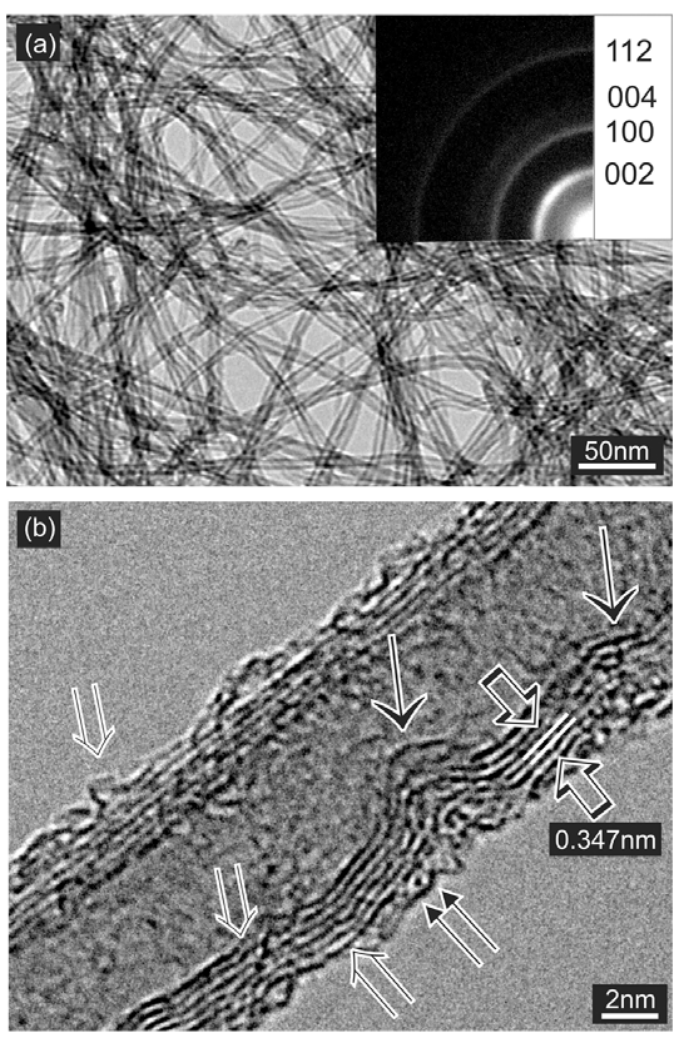

Figure 3. (a) and (b) Low-magnification and high-resolution TEM images of CNTs. The inset is the electron diffraction pattern.

of $500{ }^{\circ} \mathrm{C}$ [18], and less than that $\left(I_{\mathrm{D}} / I_{\mathrm{G}}=2.1-2.6\right)$ of CNTs grown by thermal CVD at a substrate temperature of $400-550^{\circ} \mathrm{C}$ [17]. This shows that the CNTs grown by PTCVD are of higher quality with only some structural defects.

It is interesting to explore the fast growth mechanism of CNTs at low temperature by PTCVD. Like hot filament CVD [21], PTCVD is a top-down method. It has the advantages of directly transferring thermal energy to the catalyst, heating only the substrate surface and preventing possible impurities from the filament to poison the catalyst compared to hot filament CVD. Different from traditional furnace-based thermal CVD, PTCVD offers a fast heating mode to the required temperature within seconds and enables the catalytic metal film to be nanostructured by preventing metals from been alloyed, diffused, coarsened, etc. PTCVD is purely a thermal process without the interference of plasmas. This precludes the negative effects of ion-bombardmentinduced poisoning of catalysts and etching of CNTs, which commonly occurs in plasma-based CVD. We carried out a control experiment with an extra $550 \mathrm{~V} / 90 \mathrm{~mA}$ DC plasma. Only a few CNTs are found on the substrate. The DC plasma does not enhance the CNT growth as expected. Meanwhile, both theoretical calculations and experimental studies have reported that dual metal catalysts have higher activities compared to single metals. One of the dual metals could enhance the nucleation of CNTs and the other could essentially increase the CNT growth [22]. They usually have a lower melting point and specifically benefit lowtemperature growth of CNTs by lowering the activation energy
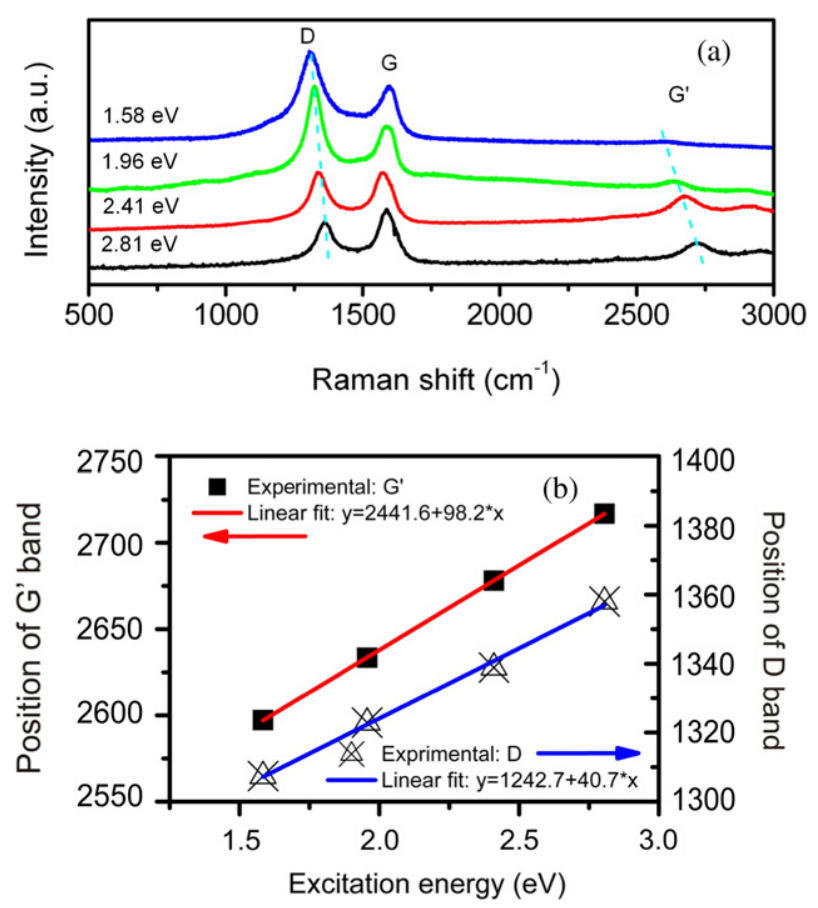

Figure 4. (a) Raman spectra of CNTs with excitation by various wavelength lasers and (b) the energy dispersion of peak positions of $\mathrm{D}$ and $\mathrm{G}^{\prime}$ bands.

due to the synergistic effects of the bimetals. Fe/Ti binary catalysts have been used to catalytically grow CNTs. However, they demonstrate different activities for CNT growth, which are critically dependent on the deposition method [23, 24]. In traditional thermal $\mathrm{CVD}, \mathrm{Fe} / \mathrm{Ti}$ catalysts are completely inactive because $\mathrm{Ti}$ has a high solubility in $\mathrm{Fe}$, leading to the formation of a large particle. In contrast, $\mathrm{Fe} / \mathrm{Ti}$ can catalytically grow mm long CNTs by grid-inserted plasma CVD at $600^{\circ} \mathrm{C}$. It is worth noting that, at the substrate temperature of $400^{\circ} \mathrm{C}$, the growth rate is only around $0.1 \mu \mathrm{m} \mathrm{min}^{-1}, 13$ times smaller than values recorded in this study. Here, in our PTCVD system, Fe/Ti bilayer thin films absorb incident light energy, interdiffuse and rapidly form a solid solution, which can be shown by annealing the sample in an $\mathrm{H}_{2}$ ambient. Figure 5 shows AFM topographic images of an as-sputtered $\mathrm{Fe} / \mathrm{Ti}$ bilayer film and an $\mathrm{H}_{2}$ annealed film at $370{ }^{\circ} \mathrm{C}$ for $3 \mathrm{~min}$, which have a roughness of $0.71 \pm 0.16 \mathrm{~nm}$ and $0.49 \pm 0.09 \mathrm{~nm}$, respectively. Different from traditional thermal CVD [11], the annealed sample is smoother than the pristine one. This indicates that the sputtered nanoclusters in the Fe and Ti films migrate, mix and ripen, resulting in a 'solid solution', which is made of uniformly, dense and fine Fe/Ti nanocatalysts rather than isolated large nanoparticles formed by traditional bottomup heating [11]. This ensures that the CNTs catalytically grow via a solid surface reaction with $\mathrm{C}_{2} \mathrm{H}_{2}$ [15]. The high density of nanocatalysts and the high CNT yield result in their vertical alignment, possibly aided by van der Waals interactions of adjacent CNTs with each other. Another possible mechanism of rapid CNT growth is ascribed to the formation of a ternary solid solution of highly active Ti-Fe$\mathrm{O}$ particles due to catalyst exposure in air for a longer time 

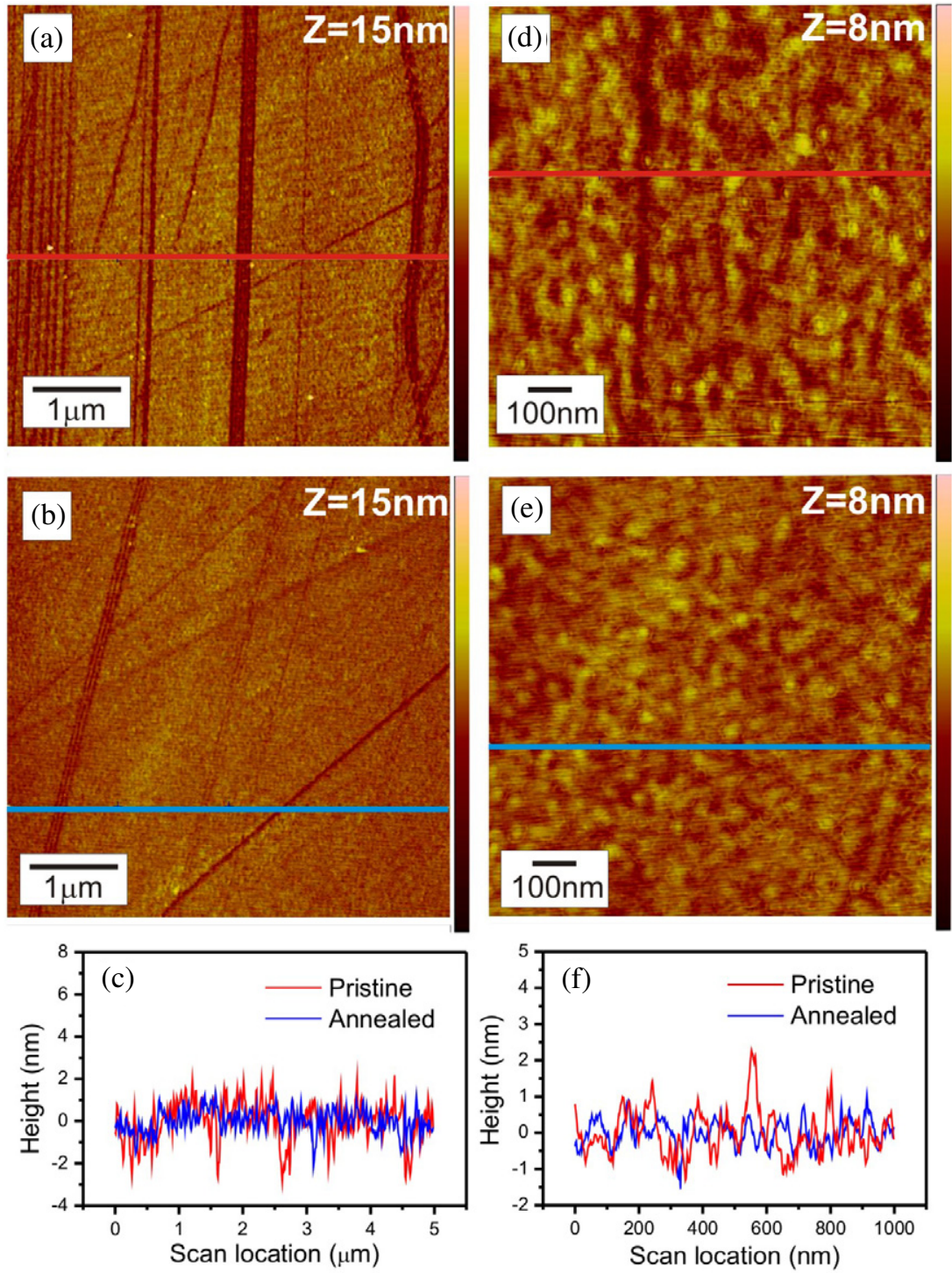

Figure 5. (a) and (b) AFM images of the pristine and $\mathrm{H}_{2}$ annealed $\mathrm{Fe} / \mathrm{Ti}$ thin film at $370{ }^{\circ} \mathrm{C}$, respectively; (d) and (e) enlarged $\mathrm{AFM}$ images of (a) and (b), respectively. (c) and (f) Line scan profiles taken from red and blue lines in the images (a), (b) and (d), (e), respectively.

period (more than one year) and without an $\mathrm{H}_{2}$ pre-reduction process [25]. Details of the rapid low-temperature growth mechanism of CNTs are not so clear. However, it is predicted that the growth rate would have a nonlinear relationship with time [26], different from a standard CVD system operating in a bottom-up heating mode, because the growth will be different as the growing CNTs can effectively absorb the light energy better and further increase the 'local' growth temperature resulting in the high rate of growth. When the substrate temperature is increased to $400{ }^{\circ} \mathrm{C}$, the growth rate can reach $2.1 \mu \mathrm{m} \mathrm{min}^{-1}$. The lowest growth temperature could be room temperature [8], but on $\mathrm{Ni}$ nanoclusters high-quality CNTs can be directly grown at less than $350^{\circ} \mathrm{C}$ by optically assisted DC plasma [14]. In this PTCVD growth system, the substrate temperature is significantly affected by the working pressure. At low pressures down to around $10^{-4}$ Torr, there is less expedient heat removed by the conventional gas flows and the substrate temperature can be up to $700-800^{\circ} \mathrm{C}$, giving high-quality single-wall CNT growth. Influence of various growth parameters such as time, temperature, pressure, gas composition and catalysts on the growth rate are being investigated in detail.

The field emission measurement was carried out in a vacuum chamber with a base pressure below $10^{-6}$ Torr at room temperature by using a diode configuration with a $1 \mathrm{~mm}$ diameter stainless steel tip as the anode. The distance between the tip and the cathode was controlled at $50-100 \mu \mathrm{m}$ by a digital micrometre controller with a $2.5 \mu \mathrm{m}$ step. A small amount of silver paste was put on the top corner of the sample to make good contact between the CNT surface and the cathode stage. Figure 6 shows the relation of emission current density as a function of the applied electrical field of CNTs. The threshold field at the current density of $10 \mu \mathrm{A} \mathrm{cm}^{-2}$ is

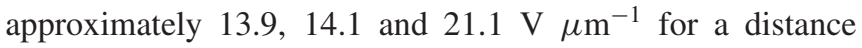
between the anode and cathode of 50, 75 and $100 \mu \mathrm{m}$, respectively. The values are close that of carbon nanoflake 


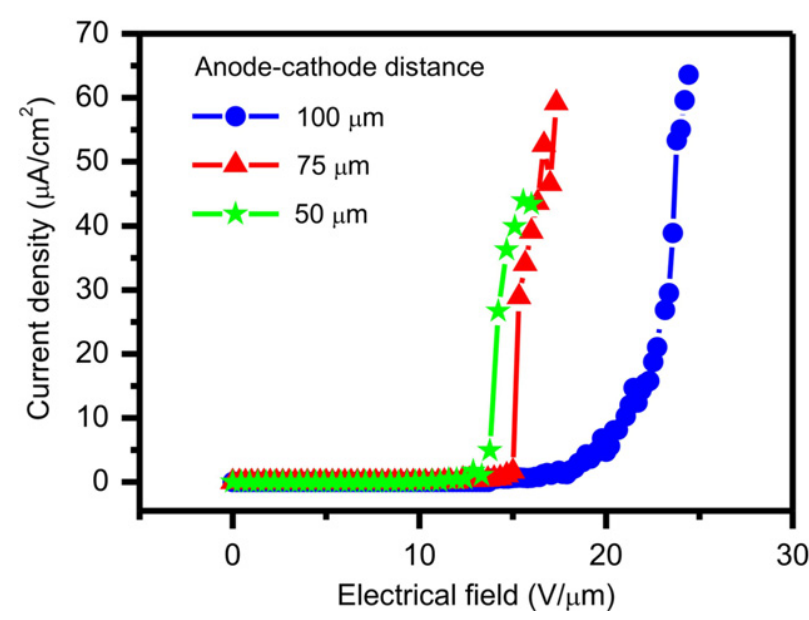

Figure 6. Emission current density as a function of applied electrical field for CNTs.

films [27], larger than that of high-temperature-grown CNTs and other carbon nanostructures $[21,28]$. The higher threshold field is believed due to the following three reasons: (1) the high density (about $10^{11}-10^{12} \mathrm{~cm}^{-2}$ ) of CNTs leads to the screening effect around the CNT tips and significantly decreases the field enhancement factor [29], (2) lower crystalline quality of CNTs affects the electron transport and emission and (3) closed cap and encapsulated metal could worsen the emitting site and the work function of the CNT tips. Thus, it is necessary for practical applications of CNTs to control their density and further improve their crystalline quality.

\section{Conclusions}

Vertically aligned CNT forests have been grown at $370^{\circ} \mathrm{C}$ by a one-step PTCVD method. The growth rate is as high as $1.3 \mu \mathrm{m} \mathrm{min}^{-1}$, being faster than most other thermal CVD methods. The CNTs are composed of few-layer crystalline graphene sheets with a 5-6 nm diameter hollow interior with some structural defects ascribed to the low growth temperature. Raman scattering provides supporting evidence that the asgrown CNTs are of high quality, better than CNTs grown at higher temperatures by traditional CVD methods. AFM topography studies confirm the fast top-down heating mode of the PTCVD leads to the formation of an Fe/Ti uniform solid solution, which greatly improves the CNT growth. The PTCVD growth method of CNTs at low temperatures offers the potential for exploiting the integration of high-quality CNTs into CMOS devices.

\section{Acknowledgments}

The authors would like to thank the EPSRC for financial supports via a Portfolio Partnership Award. We also acknowledge the support received from Surrey NanoSystems Ltd UK in conducting this research.

\section{References}

[1] Yokoyama D, Iwasaki T, Yoshida T and Kawarada H 2007 Appl. Phys. Lett. 91263101

[2] Li J, Ye Q, Cassell A, Ng H T, Stevens R, Han J and Meyyappan M 2003 Appl. Phys. Lett. 822491

[3] Vohs J K, Brege J J, Raymond J E, Brown A E, Williams G L and Fahlman B D 2004 J. Am. Chem. Soc. 1269936

[4] Rummeli M H et al 2005 Nano Lett. 51209

[5] Chiang W H and Sankaran R M 2008 Adv. Mater. 204857

[6] Hofmann S, Ducati C, Robertson J and Kleinsorge B 2003 Appl. Phys. Lett. $\mathbf{8 3} 135$

[7] Chen G Y, Poa C H P, Henley S J, Stolojan V, Silva S R P and Haq S 2005 Appl. Phys. Lett. 87253115

[8] Boskovic B O, Stolojan V, Khan R U A, Haq S and Silva S R P 2002 Nat. Mater. 1165

[9] Minea T M, Poin S, Granier A and Touzeau M 2004 Appl. Phys. Lett. 851244

[10] Levchenko I, Ostrikov K, Keidar M and Cvelbar U 2008 J. Phys. D: Appl. Phys. 41132004

[11] Cantoro M, Hofmann S, Pisana S, Scardaci V, Parvez A, Ducati C, Ferrari A C, Blackburn A M, Wang K Y and Robertson J 2006 Nano Lett. 61107

[12] Nessim G D, Seita M, O’Brien K P, Hart A J, Bonaparte R K, Mitchell R R and Thompson C V 2009 Nano Lett. 93398

[13] Chen G Y, Stolojan V and Silva S R P 2010 J. Nanosci. Nanotechnol. 103952

[14] Chen G Y, Jensen B, Stolojan V and Silva S R P 2010 Carbon 49280

[15] Stolojan V, Tison Y, Chen G Y and Silva S R P 2006 Nano Lett. 61837

[16] Shang N G, Milne W I and Jiang X 2007 J. Am. Chem. Soc. 1298907

[17] Ziebro J, Lukasiewicz I, Borowiak-Palen E and Michalkiewicz B 2010 Nanotechnology 21145308

[18] Kim C D, Jang H S, Lee H R and Kim D H 2007 Mater. Lett. 612075

[19] Dresselhaus M S, Dresselhaus G, Jorio A, Filho A G S and Saito R 2002 Carbon 402043

[20] Sato K, Saito R, Oyama Y, Jiang J, Cançado L G, Pimenta M A, Jorio A, Samsonize G G, Dresselhaus G and Dresselhaus M S 2006 Chem. Phys. Lett. 427117

[21] Shang N G, Li C P, Wong W K, Lee C S, Bello I and Lee S T 2002 Appl. Phys. Lett. 815024

[22] Deng W Q, Xu X and Goddard W A 2004 Nano Lett. 42331

[23] Nakayama Y, Pan L J and Takeda G 2006 Japan. J. Appl. Phys. 45369

[24] Kishimoto S, Kojima Y, Ohno Y, Sugai T, Shinohara H and Mizutani T 2005 Japan. J. Appl. Phys. 441554

[25] Gunjishima I, Inoue T, Yamamuro S, Sumiyama K and Okamoto A 2007 Japan. J. Appl. Phys. 463700

[26] Ting J M and Liao K H 2004 Chem. Phys. Lett. 396469

[27] Shang N G, Au F C K, Meng X M, Lee C S, Bello I and Lee S T 2002 Chem. Phys. Lett. 358187

[28] Shang N G, Papakonstantinou P, Wang P, Zakharov A, Palnitkar U, Lin I N, Chu M and Stamboulis A 2009 ACS Nano 31032

[29] Smith R C and Silva S R P 2009 Appl. Phys. Lett. 94133104 